\title{
Media docena de cuentos de Lope de Vega
}

\author{
JOSÉ FRADEJAS LEBRERO \\ U.N.E.D., Madrid
}

Desde hace años estoy preocupado por recopilar y estudiar los cuentecillos y fábulas que Lope de Vega incrusta en sus obras.

En alguna ocasión me he referido brevemente a alguno ${ }^{1}$, hora es pues, de empezar a publicar sistemáticamente el casi medio millar que he espigado. Pretendo hallar los antecedentes del cuento de Lope y seguir la tradición, tanto escrita como oral, hasta donde me sea posible.

Iniciamos el estudio del cuento con la versión o versiones que conocemos en las obras de Lope de Vega.

\section{Las mujeres son bellísimos animales}

La ignorancia y desconocimiento de la femineidad hacen que algún protagonista - criado en contacto con la naturaleza y sin relación con la sociedad - de la obra de Lope, denomine bello animal a la mujer.

1 «Un cuento de Don Juan Manuel y dos comedias del Siglo de Oro», Revista de Literatura, 1955, págs. 67-80; «De Don Juan Manuel a Lope de Vega», Estudios dedicados al Profesor Emilio Orozco Díaz, Granada, 1979, Tomo I, págs. 511-522; «Evolución hispánica de un cuento puertorriqueño», Anales de Literatura HispanoAmericana, IX, 10, Universidad Complutense, 1984, págs. 85-97; «Cuatro versio- 
¡Por Dios, que es bello animal

este que llaman mujer! (pág. 443a)

¡Oh, bellísimo animal!

¡Oh, semejanza de Dios (pág. 443b)

Sabroso es este licor, y bello aquel animal;

el gusto tienen igual,

ninguno siento mejor. (pág. 447a)

Ursón y Valentín (1588-1595), J. II, BAE, T. CCXXXIV.

Pero la expresión más perfecta está en este cuentecillo:

\author{
Tayco.- Cuatro rostros celestiales, \\ sin conocer lo que sea, \\ me representan la idea: \\ son divinas, no mortales. \\ Nunca aquestos animales \\ he visto; debe de ser \\ ésta la bella mujer \\ que no han querido que vea; \\ pero sea lo que sea, \\ esta vez me he de perder. \\ Nerea.- Una fiera ha descendido \\ de aquel monte. \\ Quildora.- Pues que muera \\ a nuestras manos la fiera \\ que a tus ojos se ha atrevido. \\ Tayco.- Que no me tiréis, os pido, \\ con aspectos celestiales. \\ Quildora.- Donde nacen hombres tales, \\ ¿mujeres te espantan, dí? \\ Tayco._- ¿Luego sois mujeres? \\ Quildora.- \\ Sí. \\ Tayco._ ¡Ah, qué bellos animales!
}

Los primeros mártires del Japón. J. I. BAE. CLXXXVII, pág. 323b.

El príncipe Tayco, encerrado en una torre, como Segismundo, o como los protagonistas de algunos cuentos orientales: Sendebar y aun el hijo del Rey de Alcaraz del Arcipresta de Hita (123-165): «en su vida ha conocido / ni sabe lo que es mujer»; y siente un vago anhelo de conocerla; cuando las ve por vez primera es cuando se produce este cuentecillo.

Este cuento tradicional clasificado por Thompson con el número T371 (The boy who has never seen a woman $=\mathrm{El}$ muchacho que nunca

nes de una fábula», Notas y estudios filológicos, UNED, Centro Asociado de Navarra, 1984, págs. 7-11; «Seis cuentos de origen clásico en Lope de Vega», Boletín de la Academia Puertorriqueña de la Lengua Española, XIV, 2, 1986, págs. 7-34. 
había visto una mujer) hunde sus raíces en la biografía hindú de Buda conocida como Lalita Vistara y en el mundo occidental como Vida de los santos Barlaan y Josafat. Según la versión medieval española:

Havýa un rey - dixo Teodas- que non podía aver fijo varón; e era por ende muy triste e teníase por mal andante por ello, e avýa muy grand tristeza. E avýnole asý que le nasció un fijo, e fue por ende muy alegre. Mas dixéronle los astrólogos e los philósophos, si aquel niño vyese el sol e fuego ante de diez años, que perdería la vista de los ojos e cegaría, ca en la su nasçençia lo veýen. Quando el rey oyó esto, mandó fazer una grand cueva en una peña e fizo allý meter a su fijo con sus amas por tal que no podiese ver claridat del sol fasta que fuesen conplidos los diez años. E desque fueron conplidos los diez años, sacaron el moço de la cueva e non conosçía ninguna cosa de las de este mundo. E mandó el rey que le pasasen por delante todas las cosas podyesen aver en el su reyno, e que ge las mostrasen cada día por sí, e le diesen los nombres que avýen, e feziéronlo asý.

E el infante estava en una altura non mucho grande, e podía muy bien mirar toda cosa que pasase, e estavan omnes con él para responder e dar respuesta a toda cosa que él preguntase. E commo pasavan las cosas asý ordenadamientre luego el infante dezía: «QQué cosa era aquélla?»

Dezían: «Tal cosa: omnes, o mugieres, o cavallos, o vacas, e asý de todas las otras cosas». E pasando las mugieres e las moças muy compuestas en dança, el infante demandó muy afincadamientre qué cosa eran e cómmo avýan nonbre.

E uno de los que estavan con él dixo asý reyéndose, commo por burla: «Señor, an nonbre diablos que engañan a los omnes».

E non se le olvidó al niño aquel nonbre que allý puso, mas el coraçón que las codiciava más que todas las otras cosas. E después que todas las cosas fueron pasadas, leváronlo al rey su padre, e el rey demandóle que de todas aquellas cosas qual le parescía mejor.

Respondió el infante: «Non fue cosa que tan bien me paresciese, nin que tanto codiciase para mí, commo los diablos que engañan los omnes, ca non fue en toda cosa tan apuesta.

El P. Gracián (Agudeza y arte de ingenio, Discurso LVII) se lo atribuye, como era común, a «San Juan Damasceno, que se la refirió Teudas al rey Abener». Por cierto que la cadena transmisora continúa y don Ciro Bayo (Con Dorregaray, una correría por el maestrazgo, cap. 2), copia la parte final dando incluso la fuente, el P. Gracián.

A partir del conocimiento de esta versión en Occidente se establecen dos direcciones:

La primera se continúa en el Cardenal dominico Jacques de Vitry (cuento 82, edición Crane); en la Legenda aurea de Jacobo de Vorágine (Cap. CLXX, pag. 674 de la edición Wyzewa); Recull de Eximplis, ca- 
talán del s. XV, (n. ${ }^{\circ} 141$, pág. 133); Segunda Celestina (1535) de Feliciano de Silva (Escena 31, pág. 389, ed. Chamorro):

Pues has de saber que un rey mandó a un sabio que enseñase a un hijo suyo dende que nasció, a donde no viese más que al sabio, y después que ya hombre llevólo adonde pasaban muchas cosas, y pasando unos y otros, y el hijo del rey preguntando cada cosa qué era y el sabio diciéndoselo, pasaron unas mujeres muy hermosas, y preguntó el hijo del rey: qué cosa era aquello, y el sabio dijo que diablos, pues tales hacían a los hombres; y respondió el hijo del rey: si estos son diablos, yo quiero que me lleven a mí.

Alonso de Villegas en el Fructus sanctorum (Discurso 54, De mugeres, $\mathrm{n} .^{\circ} 28$, fol. $345 \mathrm{vb}$ :

Se dice de cierto rey que le nació un hijo, y echando juicio algunos astrólogos en su nacimiento (aunque con vanidad y falsamente por ser negocio reprovado) dixéronle que si en diez años veýa la luz del sol, moriría. Él por les dar crédito hízole criar dentro de una cueva. Y pasado este tiempo, salió el moço, y admirábase de todo lo que veía: vido mugeres galanas y preguntó qué cosa eran. Y con malicia respondieron que eran demonios que llevaban almas al infierno para ser atormentadas con fuego. Estando después en la presencia del Rey su padre, y preguntándole que de lo que habia visto, qué era era lo que mejor le parecía y agradaba más, él respondió que los demonios que llevaban almas al infierno. Véase la fuerça que hace la vista de las mugeres. Lo dicho se refiere en el Promptuario de exemplos [de Juan Herolt].

$Y$ tras Lope ocurre, aunque difusamente, pero en acción, en la Jornada primera de En esta vida todo es verdad y todo mentira de don Pedro Calderón de la Barca; Heráclito al ver a Cintia exclama: «¿Qué bello animal!».

En Italia lo encontramos en la Flor de Virtudes (Trad. española en el Cancionero de J. Fernández de Hixar, cap. XXXVIII, tomo II, pág. 744), atribuido a un hijo del Emperador Casiodoro; y en II Novellino, n. ${ }^{\circ}$ 14, pág. 25 (Ed. Biblioteca Rizzoli); de él deriva esta versión española de Ramón Pérez de Ayala en Luna de miel, luna de hiel (1922), pág. 32 (Ed. Losada).

Volvió don Cástulo con un pequeño volumen.

-Este libro se llama el Novellino; está en italiano y fue escrito en el s. XIV. Buscó el pasaje, y leyó: "De cómo un rey hizo educar un hijo suyo en una cueva, y después, mostrándole todas las cosas, lo que más le plació fueron las mujeres».

A un rey le nació un hijo. Los sabios astrólogos previnieron que debía permanecer veinte años sin ver el sol. Entonces le hizo guardar y mantener en una cueva oscura. Después del dicho tiempo lo sacaron y le presentaron delante muchas cosas preciosas y doncellas hermosas, llamando cada cosa por su nombre, y de las doncellas le dijeron que eran demonios. Preguntáronle 
luego qué era lo que le agradaba más. Respondió: Los demonios. Entonces el rey se maravilló sobremanera, exclamando: ¡Cuánta tiranía y belleza en la mujer!

Una bella versión que debió de popularizarse es el Prólogo o Loa, n. ${ }^{\circ} 155$ (XXXVII), que incluye Cotarelo en su Colección de Entremeses (T. II, p. 433-434). Unos nobles peregrinos visitan Santiago y luego a un ermitaño; muere la madre de parto y el padre de tristeza, el niño es amamantado por una cierva y:

Crió el ermitaño al niño como a un hijo muy amado, pareciéndole que Dios por tal se lo había dado, instruyéndole en lo que vía convenible a buen cristiano. Crióse muy obediente, a ratos con él orando, a sus horas divirtiendo, $\mathrm{y}$ al trabajo le ayudando. Quince años allí estuvieron, sin que viesen hombre humano, cuando el ermitaño un día acordó de ir a poblado. Llevóse consigo al mozo, y del yermo le he sacado. A León, ciudad antigua, por sus pasos han llegado. Iba el mozo embebecido, hacia acá y allá mirando, y de todo lo que vía al buen viejo preguntando. Preguntóle: «¿Qué es aquello más grande que los venados?» El viejo le respondió: «Hijo, mulas y caballos». « $i \mathrm{Y}$ aquellos que nos parecen en las caras, cuerpo y brazos?» «Hombres, hijo, cual nosotros, nuestros prójimos y hermanos». Vio unas damas muy hermosas y compuestas por el cabo; luego preguntó lo que eran. Dijo el viejo: «Son diablos; Dios nos libre, por quien es, de caer entre sus manos's. Paróse algo triste el mozo; pero en fin de la ciudad a la ermita vuelta dando, andaba muy pensativo, confuso, entre sí callando. 


El viejo, cuando le vio
ir tan mustio imaginando,
le dijo: «¿Qués tu pasión?
¿Hijo, de qué estas turbado?
Dime de todo cuanto has visto
lo que más te ha contentado»:
Respondió con un suspiro:
«Los diablos que he mirado;
desde el punto que los vi
me han el corazón robado;
no me da otra cosa gusto;
siempre en ellos voy pensando.»
Yo pienso también que me oye
quien dice: «Desos diablos,
esta noche, por mi cuerpo,
vengan dos, o tres, o cuatro».
Yo, que no soy tan valiente,
con uno terné sobrado,
con tal que escoger me dejen
de los que me están mirando.

La segunda corriente no denomina diablos a las mujeres, sino ánades y gansas, y el protagonista es un novicio que acompaña al abad. Aparece por vez primera en Eudes de Cheriton (Hervieux, T. IV, pág. 409) y le sigue Boccaccio (Introducción a la Jornada IV); por esta razón no puede ser que Calderón, como decía Menéndez Pelayo, se hubiera inspirado en el Decamerón; ni Alonso de Villegas, que utiliza las dos versiones.

Una tercera versión es la que denomina a la mujer ojo del diablo, y se realiza entre dos hermanos o frailes. Aparece por vez primera en Eudes de Cheriton (Hervieux, IV, p. 285), traducido en el Libro de los exenplos por abc (n. ${ }^{\circ}$ 300-231) de Clemente Sánchez de Vercial.

La consecuencia en todos los cuentos es la que resume Todorov: «El diablo es la mujer en tanto en cuanto es objeto de deseo».

\title{
Gastar con prudencia
}

\author{
¿Hay hijo, ni le ha visto el mundo todo, \\ que sea, como yo, tan obediente? \\ no gastaré una blanca ${ }^{2}$ de otro modo \\ ni saldré de tu gusto eternamente;
}

2 Blanca $=$ Moneda de escaso valor 
yo, padre, con Prudencia me acomodo

mira, señor, si te obedezco ausente;

con Prudencia he gastado mi dinero

y todo el que me envías gastar quiero.

Sembrar en buena tierra (1616) Act. I.N.Ac. IX p. 405 b.

Es el caso que el padre escribe a su hijo estudiante y le anuncia el envío de su mesada:

Sólo agora te llevas tres mil pesos, porque vayas con tiento en el gastallos

$\mathrm{y}$ te mando, so pena de obediencia, que gastes tus dineros con prudencia.

Obsérvese que el hijo habla de Prudencia con mayúscula, y es, por tanto, nombre de mujer, su amiguita; mientras que el padre habla de prudencia con minúscula, una virtud. El chiste y la burla del cuento se producen por el juego de palabras.

Todo se explica más claramente en El donado hablador de Alonso de Alcalá Yáñez (1624):

Como el otro hijo de un buen hidalgo, a quien, enviándole su padre a Salamanca para que estudiase, dándole lo más que pudo para su curso, al salir de casa le dijo:

- Ya ves, hijo mío, la poco hacienda de tu padre. Pídote por el amor que te tengo, o como padre a quien debes obedecer, que estudies y trabajes como persona que va a Salamanca no a otra cosa, y que gastes con prudencia lo que fuere necesario.

Partióse el mozo, entró en las escuelas, cursó algunos días. Pasando por la ciudad, acertó a ver a una negra mujer que le llevó los ojos; dio en festejarla, servirla y pretenderla, gastando en eso más horas y tiempo que en los Baldos; y consumiendo el dinero que había traído para seis meses, afligido por verse sin blanca, escribió a su padre, suplicándole le socorriese con cincuenta ducados, y que no entendiere que había echado a mal lo que le había dado, pues en Dios y en su conciencia que lo había gastado con Prudencia: verdad, que así se llamaba su dama.

Parte I, cap. I BAE T. XVIII, págs. 425b-426a.

Sin duda era un cuento tradicional o al menos popular en la época, pues Baltasar Porreño se lo atribuye a Felipe II:

Consultáronle muchas veces a una persona grave para una dignidad y nunca la proveía, aunque se la pusieron en primer lugar; y viendo esto propusieron a la dicha persona, sola, en la última consulta, para que la acabase de proveer, y dixeron en ella a Su Majestad era persona de mucha prudencia; escribió a la margen:

-Propóngase otro, que ya tengo noticia de su prudencia.

Y era el caso que el susodicho estaba amancebado con una dama, llama- 
da doña Prudencia, a cuya causa nunca lo proveyó.

Dichos y hechos del Rey Felipe II. Madrid. Saeta. 1942, Pág. 138.

Lo esquematiza Francisco Asensio (Clase III, Cap. VIII, De estudiantes):

Gastaba mucho dinero un estudiante con una dama suya, llamada Prudencia; y como continuamente estuviese molestando al padre con pedirle dinero, le envió a decir mirase cómo gastase, porque iba descaeciendo mucho la casa; y él respondió:

-No sé, señor, para que son tantas reprehensiones, cuando todo lo gasto con prudencia.

\section{Sigue la tradición de Porreño el Duque de Frías:}

Representó a su Majestad el mismo tribunal diversas veces en dignidades eclesiásticas a un personaje de sangre y letras a que nunca assintió; y empeñado el Consejo, persuadido a que hacía lo mejor, repitieron su súplica, diciendo sus méritos y ciencia y cuán adornado era de prudencia.

Escribió [el rey Felipe II] al margen: «Póngase otro, sin alterar el estilo de venir uno solo, que el sujeto que me decís, su prudencia le hace incapaz de gobernar almas, tratando tan mal la suya.

Era el caso que estaba entregado con relajamiento a una dama, cuyo nombre era Prudencia.

Deleite de Discreción... Cap. I. Ed. 1764 p. 28.

En la comedia musical moderna Las de Villadiego, de González del Castillo y Muñoz Román, se juega con el nombre de la tonta, Prudencia, y del pastor, Cabrales, en un sentido irónico y humorístico bastante próximo a este cuentecillo.

Algo semejante cuenta Cansinos-Assens en La novela de un literato, T. II, p. 289:

El repórter judicial de La Corres, Enrique Jardiel, viene raras veces a la redacción.

Es un hombre simpático, locuaz, dicharachero, gordo y colorado que acredita esa Rioja de donde es natural.

Está casado con una mujer que se llama Inocencia y es cómico verle decir que él se acuesta y se levanta con la Inocencia...

\section{La mujer y el simio}

Cuentan de una mujer que a un simio tuvo afición, tratándole en ocasión 
que no pudo más hacer

que de una nave perdida

a una isla despoblada

salió, en una tabla asida,

donde fue dél regalada;

$\mathrm{y}$ al fin le quiso, querida.

Los torneos de Aragón (1597), A.I., N. Ac. X, pág. 2a

Este cuento es una parte de una narración más novelesca. No es el primer y único caso de unión entre animal y mujer: se cuenta que los habitantes del Pegú descienden de un perro que tuvo ayuntamiento con una mujer; también se cuenta el de un oso con una mujer; narraciones posterior y anterior a ésta en el Jardin de Flores curiosas de Antonio de Torquemada.

Lope ha cortado la narración en la primera parte, que marcamos, con el fin de evitar la repugnancia y dramatismo del final:

Una mujer cometió un delicto muy grave, por el cual fue condemnada en destierro para una isla deshabitada de las que comúnmente llaman las Islas de los lagartos, y llevándola en una nao de las que partían para la India, de camino, la dejaron en ella junto a la ribera, y cerca de donde parecía un monte grande y espeso, que tomaba gran cantidad de tierra. La pobre mujer, como se vio sola y desamparada y sin esperanza de poder sustentar la vida, comenzó a dar grandísimas voces, encomendándose a Dios y a Nuestra Señora que en aquella soledad y necesidad la favoreciesen, y estando en estas lamentaciones, salieron muy gran cantidad de ximios de la espesura de aquel monte, los cuales la cercaron al derredor, no sin ponerle pequeño temor y espanto. Venía entre estos ximios uno mayor que todos, y tanto que, puesto en los pies enderezando el cuerpo, era tan grande como un hombre; éste, viendo llorar la mujer, y que con el gran miedo que tenía estaba esperando la muerte, la cual tenía por muy cierta, se fue para ella y le comenzó a hacer caricias y halagos, y a darle frutas silvestres y raíces, de manera que la puso en esperanza de que los ximios no le harían daño alguno y así se fue con ellos hasta el monte, donde el ximio mayor la metió en una cueva, y allí acudían todos los otros, proveyéndola de los mantenimientos que ellos usaban y tenían, de manera que ella podía bien entretenerse con ellos y con el agua de una fuente que allí muy cerca estaba.

Hasta aquí, podemos decir, llega el cuento de Lope y se puede entender por el último verso: «y al fin le quiso, querida»; pero la narración melodramática y trágica continúa así:

Y así pasó algún tiempo, en el cual el ximio vino a aprovecharse de ella, teniendo sus ayuntamientos sin que ella fuese parte para estobárselo, porque temía de ser luego muerta, y de esta manera se hizo preñada y parió en dos veces dos hijos, los cuales, según ella decía y afirmaba, y aun según lo que después se entendió de los que vieron, hablaban y tenían uso de razón. Y siendo estos mochachos el uno de dos años y el otro de tres, acaeció a pasar por allí otra nao que volvía de la India, y los marineros, que llevaban falta de 
agua y tenian noticia de aquella fuente que en la isla estaba, determinaron de salir en tierra a proveerse de ella, y así, echando al agua un esquife, salieron en la isla; los ximios, como los vieron, escondiéronse, pero la mujer, esforzándose y determinando de dejar aquella vida que tanto tiempo tan contra de su voluntad había tenido, fuese dando voces para los marineros, los cuales, reconociendo ser mujer, la esperaron y la llevaron consigo y la metieron en la nao. Los ximios salieron todos a la ribera, siendo tan grande la multitud de ellos como de un ejército, y el mayor, con el amor y afición bestial que con la mujer tenía, se metió tras ella por el agua, tanto que corrió muy gran peligro de ahogarse, y las voces y aullidos que daba y los chirriados bien daban a entender que sentía la burla que se le había hecho; y viendo que no le aprovechaba, y que los de la nao alzaban velas y se querían partir, tomando en los brazos el menor de los hijos, y metiéndose por el agua todo lo que pudo, lo tuvo en alto un gran rato, y después lo arrojó en la mar, donde a la hora fue ahogado; y volviéndose por el otro, se tornó a entrar al mismo lugar, y estaba con él teniéndolo en alto y como amenazando que también lo ahogaría. Los marineros, movidos por el gran sentimiento de la madre y de lástima de oir llorar el mochacho, que con voces claras llamaba por ella, quisieron volver a tomarle; pero el ximio, con el temor que de ellos tenía, no osó esperarlos; antes, soltando también el muchacho en medio de las olas, se fue huyendo con todos los otros ximios, y por mucha diligencia que los marineros pusieron en salvarlo, se ahogó antes que ellos llegasen; y vueltos a la nao, supieron de la mujer todo lo que pasaba, de que no fueron poco maravillados, y con esto se partieron, y llegando a Portugal dieron noticia de lo que habían visto y entendido de este caso. La mujer fue luego presa, $\mathrm{y}$, habiéndole tomado su dicho, y confesado, la condenaron a que, atento que había quebrado el destierro y que, juntamente, había cometido un delito tan enorme como era el del ximio, fue[se] quemada por ello. Pero Hierónimo Capo de Ferro, que era en aquel tiempo Nuncio apostólico en aquel reino y después fue Cardenal, viendo que lo que había hecho fuera por conservar la vida, y que los ximios no la matasen o no la tuviesen siempre en un cautiverio perpetuo y en un pecado de que le acusaba la conciencia, suplicó al Rey le hiciese merced de perdonarla, y así se salvó, con que todo el tiempo que viviese estuviese en un monasterio, sirviendo y haciendo penitencia de sus pecados.

Tratado I, pág. 182-185 (Ed. Allegra).

Hagamos notar que estos hechos no se producen solamente en la cultura occidental; en la Miscelánea Tai-ping (China, S. VII) se incluye el cuento anónimo El mono blanco: cuando Ouyang Heh explora una región selvática, en compañía de su mujer, un gran mono blanco se la rapta y aunque la recupera, más tarde dará a luz un hijo de faz simiesca.

Hay alguna cita literaria que aún no está clara, como la de $\mathrm{La} \mathrm{Ce}$ lestina en que Sempronio dice a Calisto, emparejándolo con otros amores bestiales, a los que este califica de fablillas: «Lo de tu abuela con el ximio; ¿fablilla fue?. Testigo es el cuchillo de tu abuelo». Hasta las mentes más preclaras del S. XVI creían en la realidad de estos ayuntamientos:

Se colige ser verdad lo que muchas historias auténticas afirman: que un perro tiniendo cuenta con una mujer, la empreñó; lo mismo hizo un oso con 
una doncella que halló sola en el campo; y de un jimio que tuvo dos hijos en otra mujer; y de otra que, andándose paseando por la ribera del mar, salió un pescado del agua y la empreñó.

Huarte de San Juan, Examen de Ingenios. Parte III. Cap. XV, Ed. Rodrigo Sanz, T. II p. 415.

La secuencia de los casos nos lleva a considerar que la fuente es la obra de A. Torquemada, donde se hallan por el mismo orden. Y lo más curioso es que Huarte llama a esta obra «Historia Auténtica».

También como realidad histórica nos cuenta Voltaire una aventura de Cándido en Paraguay, en que la relación mujer-simio se establece en un ámbito de vida natural que sin embargo disuena al protagonista, no así al criado criollo que incluso alude a viejas leyendas grecolatinas:

En parlant ainsi, il ne laissa pas de manger. Le soleil se couchait. Les deux égarés entendirent quelques petits cris qui paraissainet poussés par des femmes. Ils ne savaient si ces cris étaient de douleur ou de joie; mais ils se levèrent precipitamment avec cette inquiétude et cette alarme que tout inspire dans un pays inconnu. Ces clameurs partaient de deux filles toutes nues qui couraient légèrement au bord de la prairie, tandis que deux singes les suivaient en leurs mordant les fesses. Candide fut touché de pitié; il avait appris à tirer chez les Bulgares, et il aurait abattu une noisette dans un buisson sans toucher aux feuilles. Il prend son fusil espagnol à deux coups, tire, et tue les deux singes. «Dieu soit loué, mon cher Cacambo!, j'ai délivrè d'un grand péril ces deux pauvres créatures; si j'ai commis un péché en tuant un inquisiteur et un jésuite, je l'ai bien réparé en sauvant la vie à deux filles. Ce sont peut-être deux demoiselles de condition, et cette aventure nous peut procurer de très grands avantages dans le pays».

Il allait continuer, mais sa langue devint percluse quand il vit ces deux filles embrasser tendrement les deux singes, fondre en larmes sur leur corps et remplir l'air des cris les plus doulereux. «Je ne m'attendais pas à tant de bonté d'âme», dit-il enfin à Cacambo; lequel lui répliqua: «Vous avez fait là un beau chef d'oeuvre, mon maître; vous avez tué les deux amants de ces demoiselles». «Leurs amants! Serait- il possible! Vous vous moquez de moi, Cacambo». «Mon cher maître, reprit Cacambo, vous êtes toujours étonné de tout; pourquoi trouvez-vous si étrange que dans quelques pays il y ait des singes qui obtiennent les bonnes grâces des dames? Ils sont des quarts d'hommes, comme je suis un quart d'Espagnol». «Hélas!, reprit Candide, je me souviens entendu dire à maître Pangloss qu'autrefois pareils accidents étaient arrivés, et que ces mélanges avaient produit des égipans, des faunes, des satyres; que plusieurs grands personnages de l'antiquité en avaient vu; mais je prenais pour des fables». - «Vous devez être convaincu à présent, dit $\mathrm{Ca}$ cambo, que c'est una vérité, et vous voyez comment en usent les personnes qui n'ont pas reçu una certaine éducation; tout ce que je crains, c'est que dames ne nous fassent quelque méchante affaire».

Candide. Cap. XVI.

Pero sin duda lo más significativo es que se haya recogido folklóricamente en la Provincia de Cádiz y no cabe sospechar independencia, 
pues si bien tiene detalles iniciales de tipo popular, el cuento, complejo en sí, introduce la narración incluso con el aspecto de ver a la mujer en el barco y la muerte de los otros dos hijos.

La niña huye de su padre cruel porque ha perdido una vaca, y camina y camina:

Transcurrieron dos otros años que se llevó la niña andando, y entonces, pues, llegó allí y llegó un orangután y entonce la llevó a la casita que el orangután tenía allí.

Tenía ya dieciocho años y entonces fue y estando allí, allí dentro, el orangután le puso una piedra para que ella no pudiera salí, porque como el orangután era el que tenía la fuerza, pues ella no podía salí.

Y él se fue, y le traía de comé conejos vivo y de esa cosa pa que ella comiera, y está ella pensando en su casa.

Y el padre está diciendo allí en su casa:

- ¡A dónde estará esa chiquiya?

Y dice la madre:

- Claro; como tu siempre la estaba amenzando para que no volviera si perdía alguna vaca, pues ella se habrá escondido por ahí.

Y entonces, pues, tuvo tres chiquillo que todos salían al padre, al orangután, y claro, ellos tiraban de la piedra, y como tenían la fuerza del orangután, se iban al campo a correr como el padre.

Y entonces, pues, ella estaba siempre llorando.

Pero uno de ellos no era orangután, uno de ellos era un niño y entonces estaba llorando, y entonces el otro, como era chiquillo, estaba siempre al lao de la madre.

Y un día le dice el niño a la madre:

- ¿Por que llora tanto?

Dice:

-Porque sí, porque tengo de llorá.

Dice:

- ¿Vamo a escapamo los do?

$\mathrm{Y}$ dice la madre:

-Sí

Y el niño quitó la piedra y fueron los dos corriendo, y corriendo, corriendo, vieron un barco, y dicen:

- Vamo a ve si nos admiten en el barco.

$Y$ se van al barco.

Pero al mirarlos los cogieron a los dos, y allí los vistieron, porque estaban desnudos de tanto tiempo de está fuera de su casa, a su madre y al niño también.

Conque fueron, y se iban ya, y fue el orangután y vio que habían quitado la piedra, y cogió a los dos niño y salió corriendo y lo vio que habian subido al barco.

Conque le enseñó los niño, y como vio que no hacía caso, pues fue y le rajó a los niños a ve si se volvía.

Larrea Palacín, A., Cuentos Gaditanos, Madrid, 1959, Cuento n. ${ }^{\circ}$ XXII, pág. 142.

Las relaciones de bestialidad tienen también su versión en las Mil y una noches, noches 355-357 (Ed. Vernet, T. II págs. 230-2), en que 
se nos cuenta la ninfomanía de una joven con un negro, pero sobre todo con un mono, bien que el mono es muerto por el joven que se casará con la curada ninfómana; quiza a este aspecto novelesco se refiere la cita anterior de La Celestina.

Esta coyunta ha sido clasificada por Thompson con el motivo número B 601.7, Marriage to monkey = Matrimonio con un mono.

\section{La bruja}

Para que tengáis en alta veneración la salutación Angélica de la Virgen, y siempre que se tocare a rezarla, la digáis con devoción, sabed, hijos, que escribe Paulo Guirlando que, trahiendo el demonio a una muger llamada Lucrecia de unas fiestas, que en un momento se avían hecho la noche antes, donde ese maldito género de mugeres se junta a sus bayles, lascivias y convites, tocaron en una Iglesia al Ave María, que en aquella tierra se hace siempre ésta al alba. Apenas pues el demonio oyó sonar la campana, para que el pueblo saludase a la Virgen, quando espantado bajó a la tierra la mísera muger, y la dejó en un campo de espinas y secas hierbas a la orilla de un río, donde estuvo hasta que un mancebo, que la conocía, passando por allí acaso, avergonzándose de verla desnuda y los cabellos sueltos, con que procuraba encubrirse, le dio su capa. Ella pretendió engañarle contándole varia quimeras que, pareciéndole todas fábulas, jamás quiso llevarla hasta que, ella vencida de la necesidad, le dixo cómo iba con otras muchas algunas noches a semejantes actos, y que volviéndola el demonio aquella mañana, por haber oído tocar a la Salutación de la Virgen, la havía desamparado. Él prometió callar el suceso dándole su palabra; pero como después lo manifestase a un amigo, él lo dixo a la Justicia, y el referido Doctor conoció del caso, abrasando su cuerpo y el de otras muchas.

El peregrino en su patria, libro II, ed. Avalle Arce, pág. 161.

Este suceso novelesco sin duda era corriente en la literatura oral sobre supesticiones, pues aunque Lope da la fuente, sin duda no lo tomó directamente, sino de otro libro muy difundido y que Cervantes recuerda en la destrucción de la librería de Don Quijote (Parte 1, cap. VI, pág. 69, ed. Riquer); me refiero al Jardín de Flores curiosas de Antino de Torquemada, publicado en Salamanca en 1570:

Y para que entendáis por ejemplo, quiero deciros lo que cuenta Fray Alonso de Castro, por autoridad de Pablo Grillando, en el tratado De herecticis, y es que una mujer en Italia, que había probado esta arte diabólica, vino a ser llevada por el demonio a hallarse en uno de sus ayuntamientos, y como ya volviese para su casa, habiendo gozado de aquellos sucios y abominables deleites, siendo cerca de la mañana, sonó la campana que en Italia se acostumbra a tañer a aquella hora, para demostrar al pueblo que hagan oración, y en oyendo el sonido, el demonio que la traía la soltó y se fue, y ella quedó en un campo muy lleno de espinas, cerca de la ribera de un río, y un mancebo que la conocía muy bien, acaso pasó entonces por allí de camino; y como ella le viese, llamóle, rogándole que se llegase a donde estaba, y el mancebo, viéndole desnuda y los cabellos esparcidos por las espaldas y por los pechos, 
pareciéndole ser alguna visión, temía de llegarse a ella; pero, al fin, con lloros y halagos, le venció, nombrándose por su nombre y haciéndole entender que era Lucrecia, porque asi se llamaba. El mancebo, muy maravillado, llegándose a ella, le preguntó qué era lo que había acaecido para estar de aquella manera y en aquel lugar tan apartado, y ella quiso encubrirlo, fingiendo algunas mentiras para disimular la verdad; y como al mancebo le pareciese que todas eran ficciones, díxole que ninguna cosa haria por ella si abiertamente no le confesaba la verdad de todo. Y así, viendo que su mentir no le aprovechaba, prometió decirle lo que le pasaba, con que él también le prometiese de tenerlo perpetuamente secreto; y como el mancebo se lo asegurase con juramento, ello le dio crédito y le contó llanamente todo lo que había pasado, y cómo fuera llevada por el demonio a hallarse en aquel ayuntamiento de deleites con las otras brujas, y que a la vuelta al demonio la habia desamparado, en oyendo el son de la campana. El mancebo, entendido el negocio, la llevó secretamente hasta ponerla en su casa, sin que nadie la viese, y ella le dio muchos dones porque no la descubriese. Pero, finalmente, él, fiándose de un amigo suyo, le contó lo que pasaba, y éste lo dijo a otro, y así, de mano en mano, vino a divulgarse, de manera que fue presa y castigada de su delito.

Coloquio III, ed. Allegra, pàgs. 318-319.

Peyton, en su edición de El Peregrino, no aclara nada sobre Paulo Guillando; es Avalle Arce quien cita la obra: Paulus Guillandus, Tractatus de hereticis et sortilegiis, Lyon 1545, fol. XLII-XLIII. En esta versión de Torquemada se nos dice que lo toma de Fray Alonso de Castro, sin duda de su obra De sortilegiis et maleificiis et eorumque punitione, Lyon 1558; y no del libro que aquí menciona, De hereticis, que debe referirse a De iusta haereticorum punitione, dedicado anteriormente a Carlos V.

Se encuentra esta historia también en Menghi (Bolonia 1582), Libro II, Cap. XLV, págs. 447-448-y (Venecia, 1595), id. págs. 409-411. En el mismo capítulo cuenta Menghi algunos otros relatos escrito por P. Guillandus.

\section{El que se cree muerto}

Señor, razón tienes; nadie te la niega; que mueras es justo. ¡Muere, date priesa!Pero si es tan larga la jornada, alienta y come un bocado ¿Come ya! No seas como un caballero que dio en ese tema, y de no comer juró, si no fuera que Adán lo mandase; 


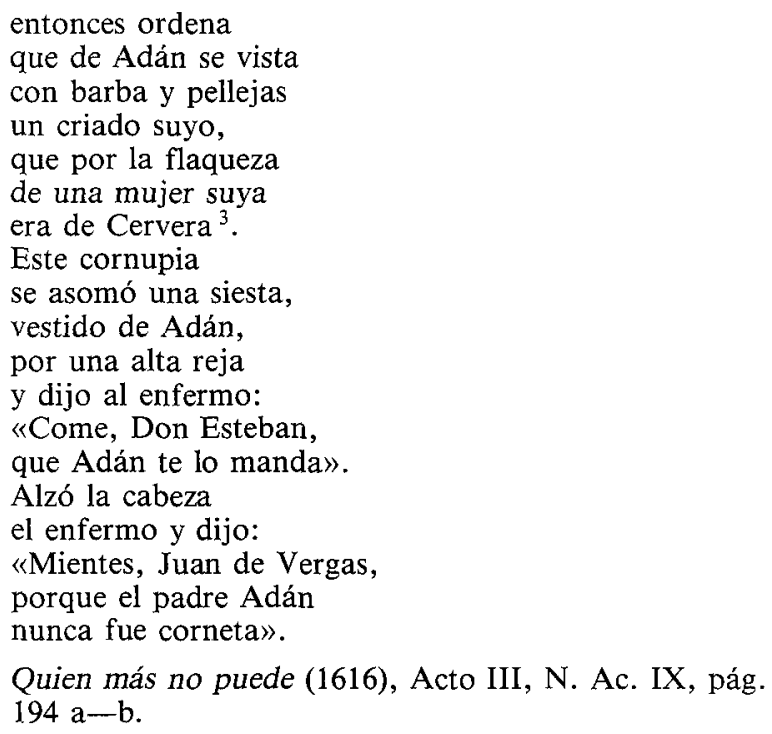

Quien más no puede (1616), Acto III, N. Ac. IX, pág. 194 a-b.

Esta comedia basada en el refrán: «Quien más no puede, morir se deja», tiene una contrapartida burlesca: «Quien más no puede, con su mujer se acuesta».

En este cuentecillo hay unos aspectos burlescos y se puede observar que realmente consta de dos motivos:

1) El muerto (loco o apasionado que se finge o cree) no quiere comer

2) Es preciso que otro, disfrazado de muerto, le haga comer.

En Lope hay una variante sustancial (la respuesta a la invitación : a comer es un insulto que al referirse a Adán lo denomina corneta $=$ cornudo) que no se observa en ninguno versión conocida. Hay pues una recreación irónica en esta obrita de Lope.

La primera versión que conozco se atribuye al Príncipe Don Juan Manuel (1282-1349), incluida en El Conde Lucanor en la edición del Conde de Puñonrostro (Vigo, 1902), cuento n. ${ }^{\circ}$ LIII, págs. 202-205 y que reproduce $H$. Knust (1900) págs. 289-291:

3 Cervera, cornucopia.-Está refiriéndose a la infidelidad de la mujer de Don Esteban Cervera, al criado que le pone los cuernos. Por eso el que Adán sea corneta (= cornudo) es anfibológico, y quizá se refiera a sí mismo. En La Lena de Alonso Velázquez de Velasco (1602) abundan estos nombres eufemísitcos: Cervino, Cornelio, Bezerrica, Aries, Morueco, Vigamón, Violante, Inocencio. 
De la imaginación que puede sacar a omne de entendimiento, e non se puede tornar de ligero sinon commo aquí dise. Contesció esto a un omne: Un omne estaba doliente e començó a pensar en la muerte de guisa que pensó que era muerto. E así fue que un día levantóse su muger y díxole que si quería comer. E él díxole bravamente que veía que estaba muerto, ie preguntávale si quería comer; $\mathrm{E}$ ella díxole que, pues flabava, que vivo estava. E él porfiava que estava muerto e dixiéndole que fuese a llamar a sus parientes e que les fisiese saber commo era muerto e que'l fisiesen onrra al su enterramiento. E ella díxole que estava loco e fuera de su entendimiento. E disiendo estas rasones partióse dél et guisó de comer e comió ella. E él non lo quiso nada. Otro día, desque ella se levantó, fabló con él, e díxole estas mesmas rasones. E otro día eso mismo díxole que se levantase. E él díxole: “`Verés qué loca muger esta! Vee que estó muerto e díseme que me levante. Ve agora, llama mis parientes e diles commo so muerto y que me vengan a faser onrra». E ella veyendo que enflaquecía e no quería comer, dixo entre si: [por que] este omne no muera por mal recabdo, quiero ir llamar sus parientes, e pongan recabdo en él. E lu[e]go fue y llamólos disiendo que su marido estaba fuera de entendimiento e desía que los llamase quel' fuesen faser onrra. E ellos ayuntáronse e fuéronlo a ver. E desque entraron por su casa dixiéronle: «Amigo, ¿cómmo estades?» E él díxole: «Veres en ora mala. ¡Veen qu' estó muerto e dísenme que commo estó! ¿Non vedes qu' estó muerto? Levadme a la iglesia e fasedme mi onrra». E ellos, dequ'esto oyeron, començaron a reyr disiéndol' qu' estava fuera del su entendimiento, e con esto fueron a llamar al físico que lo viese. E él vino luego e era gran sabidor. E desque llegó a él [e] oyó aquellas palabras que desía, díxole: «Mal fasen enterrarvos, ca muerto estades vos. E así, amigo, yo les diré agora que vos lieven a la iglesia e vos entierren onrradamente». E dixole aquel omne: «A,sennor, vos me entendedes bien, ca estos otros no veen commo estó muerto, et vos sí». $\mathrm{E}$ partióse de allí el físico, e su muger e sus parientes ayuntados todos díxoles: «Amigos, sabed qu' este omne pensó tanto en la muerte que verdaderamente tiene qu' es muerto. E omne del mundo non lo podría así sacar de aquella imaginación, pero bannaldo e levaldo a la iglesia a viésperas. $E$ en la noche yo faré alguna cosa que torne a su entendimiento». E ellos fisiéronlo así. E desque lo ovieron bannado e puesto en la cama, díxoles que por qué non traían el clérigo. E dixiéronle que mejor era quel' fisiesen su onrra en la iglesia que non en casa. E él díxoles que bien desian. E así lo levaron e lo pusieron en la iglesia e fisieron así su onrra complida e sus candelas e todo su recabdo e estudieron alli con él fasta que anocheció. E en la noche dieron a entender que se yvan todos. E cerravan la iglesia. E fincaron allí fasta seys o siete de sus parientes e pusiéronse nonbres de otros sus conocientes e amigos que eran muertos e vistiéronse sendas mortajas de lienço e estudieron allí. Esto todo fue por mandado del físico. E luego el físico dioles una jarra de letuario confortativo de cosas que esforçasen el engenio e le tornasen a su memoria. E fisieron lo que les mandó el físico. En esta manera quando fue bien noche vistiéronse aquellos omnes que fincaron en la iglesia sus mortajas e andavan por la iglesia e andando davan del pie al ataúd en que estava metido. E quando él los sintió, dixo: «¿Quién anda aý?» E ellos dixiéronle: «Fulán e fulán tus amigos, que bien sabes que somos muertos. Liéva(te), andarás aquí con nosotros». E desque los vido con sus mortajas creyólos e andava con ellos. E desque andudieron una pieça dixo uno a otro calladamente: come más, e el otro díxo[lo] al otro, e así todos fasta que lo oyó él, e díxoles: «¿Cómmo? ¿Los muertos comen?». E ellos dixéronle: «Los muertos comen muy dulces manjares que an en el paraýso terrenal, e darte emos a comer dello». E luego 
fue uno e troxo la jarra del letuario y comió cada uno un poco e diéronle a él un pedaço bueno e comió. E desque lo vieron comido dixiéronle que se querían yr e metiéronlo en su ataúd e escondiéronse en la iglesia (e) callando echarónse a dormir. E desque fue de mannana levantarónse e abrieron el iglesia. E el dormió también después que comió el letuario fasta quel' despertaron. E dende llamaron al clérigo e dieron a entender que lo levavan a soterrar. E desque despertó, dixo: «Amigos, ¿do me leváis o quién me truxo aquí?» E fallóse en su acuerdo. E desquel' contaron la manera, maravillóse ende mucho. E así vivió toda su vida en su acuerdo commo ante. Porque se demuestra que la ymaginación saca a omne de entendimiento.

En el siglo XVI la volvemos a encontrar en El estudioso cortesano (1573) del humanista aragonés Lorenzo Palmireno, haciendo protagonista a Levino Lemnio, lo cual nos hace pensar en una posible fuente clásica.

En una grave enfermedad de un caballero, que de manía se daba a entender que era muerto, se juntaron doctores, para hacerle comiesse, porque no quería, diziendo que los muertos no comen. Ellos se despidieron. Acudió Levino Lemnio sin ser llamado, diziendo:

-Yo haré comer nuestro enfermo si hazéis lo que os diré. Hazed que en la cámara haya poca lumbre, [pre]paren una mesa con buenos manjares, y una escudilla de muy buena presa, con ciertos polvillos que yo ordenaré, que le den sueño. Estado yo allí vengan algunos amortajados. En fin, dándoles la orden vinieron.

Dixo el enfermo:

- ¿Quién sois vosotros?

Respondieron:

-Somos la muerte y queremos comer.

Dijo él:

- ¿Qué, los muertos comen?

Dizen ellos:

- Miraldo.

Él, muy prompto viéndolos de tan buena gana, dixo:

-Yo también.

Acudieron con el brebaje que tengo dicho, y sosego hasta el dia siguiente, comió y poco a poco convaleció.

Esto ya vees que no era medicina, sino prudencia in agilibus.

Estudioso cortesano Libro I, págs. 22-23.

Otra versión hallamos en el Fructus sanctorum (1594) de Alonso de Villegas, cuya fuente es el Pontano, lo cual puede acentuar la sospecha de un origen clásico que mencionábamos antes:

Dio en una melancolía cierto hombre, que fue dezir que estaba muerto, y porque los muertos no comen ni beben, no quería beber ni comer. Passó en esto algunos días y estaba para dar el alma. Visto el caso por un discreto médico, usó deste aviso: Concertóse con otro hombre que dixesse que estaba muerto, y púsole en otra cama junto a la del melancólico, y habiendo platicado los dos, y convenido que ambos estaban muertos, el del concierto pidió de comer y truxéronselo. El otro dixo: pues, ¿y los muertos comen? Respon- 
dió el otro: sí, que de algunos días a esta parte se usa que coman y beban los muertos. Con esto comió y bebió, estando mirando el melancólico, el cual dixo: comer?

Luego, ¿también yo puedo aprovecharme de esa nueva costumbre y

Sí, dixo el otro. Y con esto comió y bebió, y a pocos días estuvo sano.

Dízelo Pontano, libro IV, cap. XI De Prudencia. (Discurso 7, de avisos de dichos y hechos, $n .^{\circ} 43$, fol. 39).

Con posteriodad a Lope, en el siglo XVIII, lo volverá a recordar de forma tradicional el Duque de Frías en su Deleite de la discreción:

Dio un enfermo en la manía de no querer comer, diciendo que había fallecido, y que los muertos no necesitaban de alimento. El prudente médico que le curaba, viéndole acabar sin remedio, dispuso que otro hombre, amortajado en forma de cadáver, se apareciese; hízose assí, advirtiólo el doliente, y hallándose con aquel nuevo compañero, preguntó quién era. Dixo, que un difunto, y sin estrañarlo, empezaron sus pláticas del otro mundo; a breve rato el muerto fingido pidió de comer; traxéronle una polla, viólo el demente y admirado dixo: ¿Qué es esto? ¿Los difuntos comen? Sí, hermano, respondió essotro, que así lo manda Dios; pues comamos todos; y con esta traza convaleció.

Duque de Frías, Deleite (1743), capítulo VII, p. 297.

\section{El que no conocía el miedo}

Difundidísimo debía de estar el cuento del hombre sin miedo que, pasando una noche en una casa deshabitada, ve cómo caen los cuartos de un hombre sin amedrentarse. Lope alude a él cuatro veces.

1. Galindo ¡Ha, pobre seso echizado!

Mas que ha de darse el cuitado

como los cuartos de Osorio.

Lope de Vega, La prueba de los amigos (1604), ed. Simpson, Madrid, 1934, vs. 1964-66.

2. Don Lope Te suplico por Él (Dios) que si delante vieses de ti, mientras el fin te digo, las sombras que vio Osorio el estudiante, no despliegues los labios.

Don Vasco Primo amigo, hermano, ivive Dios!, de estar a todo como una piedra, y que a callar me obligo si viese descender del propio modo los cuartos de aquel hombre a media noche. Lope de Vega, Los Porceles de Murcia (¿1604-1608?), Acad, t. 11, p. $579 \mathrm{ab}$.

3. Lisardo De aquel Osorio habréis la historia oído que vio caer el hombre cuarto a cuarto: 
lo mismo a mi temor le ha sucedido, con que de amor el pensamiento aparto.

Lope de Vega, Quien ama no haga fieros (¿1620-1622?), AcadN, t. 13, p. 413b.

4. (Aparece un brazo con una corona dorada y dice una voz dentro):

Voz. - Toma.

Bamba.- Tomaste, eso no.

Voz.- Caeré.

Bamba. - Cae si te agrada.

Comedia de Bamba (1598) J.L. BAE, 195, pág. 305b.

Obsérvese que aquí no se alude al modo de presentarse las partes, sino que se refiere a la corona.

Pero que el cuento era popular lo demuestra el que lo mencione o aluda a él Luis Martín de la Plaza:

Decís bien, y aun es notorio

por nombres averiguados

de vuestro antiguo abolorio,

que os viene por dos costados

el ser Castilla y Osorio,

Cancionero Antequerano (1627-1628) p. 234.

Y don Francisco de Quevedo por dos veces, al menos:

Los cuartos de los Osorios

eran los de la Quincoces

que se andaban cayendo

a lo títere de goznes.

Romance «Sepan cuantos, sepan cuantas» (Ed. Blecua. Planeta p. 827.

$\mathrm{Y}$ en la «Fiesta en que cayeron todos los toreadores»:

Perce que toreban

los cuartos de los Osorios. (Id. p. 770).

Ha sido J.B. Avalle quien ha dado con una versión de este cuento en el siglo XVI; incluida como leyenda genealógica en el manuscrito de las Batallas y Quincuagenas de Gonzalo Fernández de Oviedo:

Vamos a essotro cuento del encantado, de donde otros dicen que pende el nombre deste apellido, atribuydo a Osorio, la cual fábula me contó un cavallero de valor y deste linaxe muchos años ha, y dize así:

Un gran señor de donde deçendemos nosotros fue a cercar una villa y puso su exército sobre ella y túvola en gran estrecho o tal necesidad puesta que los cercados, por se evadir de su travaxo, y saviendo que éste era un señor atrevido y confiado de su esfuerzo, vernía en el partido que le movieran, con que ellos se librasen y él muriese, y enviáronle sus embaxadores y mandáronles que le dixesse[n] assí: 
«Señor, en nuestra república está una casa antigua y sumptuosa en que de día todos los que quieren entran y salen y están a su plaçer sin impedimento ni temor alguno; pero después que el sol se pone, ninguno osa quedar en esa casa, porque a otro día le hallan muerto sin saver quién le mata: y entre nosotros se estima que esta plaga çesará, según nuestros pasados dixeron, quando un cavallero osado y sin temor ahí velare una noche, y fuere tan venturoso que quede vivo. Nosotros savemos que vuestro esfuerzo y persona es de tanto valor, y la experiençia lo ha mostrado, que si cavallero ay en el mundo que con esta empresa salga soys vos; y si vuestra ventura y nuestra fuere que seáis aquel que escape de tal vigilia y trançe, nuestra república sería bienauenturada en teneros por señor, y así os envía a deçir y ofreçer que si queréis estar una noche en la casa ya dicha, y quedáredes vivo, que luego otro día sin detenimiento alguno se os entregarán las llaves y fuerças, y unánime se os entregarán todos por vuestros vasallos perpetuamente, con que les guardéis sus fueros y los tengáis en justicia, como si heredárades este señorío y fuera de vuestro patrimonio e abolengo y de tiempo inmemorial justamente adquirido».

El cavallero lo aceptó, y se dieron las reenes y seguridades a contento de las partes para tener y guardar lo capitulado, y señalaron el día para la vigilia ya dicha.

El cavallero, como cathólico, se confesó y comulgó y ordenó su testamento y determinó de poner por obra su empresa, aunque sus amigos y consexeros se lo estorvavan dándole muchas razones para que no lo hiziese. A los quales dixo:

«-Mirad, lo que yo tengo entendido de la batalla noturna es que yo tengo que pelear con el diablo, y ese contraste cada día le tenemos, y sé que el demonio no tiene más poder ni fuerza de la que Dios permite que tenga, y ese mismo Dios me la dará a mí para echar de su casa al diablo y convertirlo en templo y iglesia donde Jeschristo se mire y alabe. Yo lo prometí, y el cavallero y hombre de vergüença ha de cumplir lo que promete, y así lo haré yo, así por lo que tengo dicho como para atajar la guerra y que no muera más gente de los nuestros ni de los contrarios».

$Y$ así entró en la casa al templo asignado, queriéndose poner el sol, armado de fe christiana y de todas las armas ofensivas y defensivas que los cavalleros hombres de armas suelen exercitar, y hiço poner una hacha encendida en un candelero y otra en otro, a los estremos de la sala donde se esperava el peligro, en la cumbre de la cual havía un aguxero oscuro y çierto desván bien alto. Y después que allí le dexaron solo, él quedó paseándose y rezando sus devociones.

Y dende a tres o cuatro horas que allí estava, oyó grande estruendo y temblores en toda la casa, y pasado aquello una voz temerosa que decía: « ¿Cayré, cayré»; e aquella voz sonava en lo alto de aquella sala. Y el cavallero se comenzó a asignar y santiguar y encomendarse a Dios, y tomó una hacha de armas en la mano, que tenía arrimada a la pared, y luego tornó a oyr aquella voz más terrible, diçiendo: «Cayré, cayré!». Y tantas veces lo dijo que, importunándose el cavallero, y deseando ver ya el fin de la cosa, dijo: "Caed quando quisiéredes». Y luego con grande estruendo cayó un cuarto de hombre, o de humana efigie, membrudo y gigante, saltando por el suelo de una parte a otra. Y el cavallero con la hacha lo desviava de sí. Y después oyó la misma voz que tornó a deçir: "Cayré, cayré!». Y el cavallero respondió y di- 
xo: «Caed», y cayó otro cuarto, y juntándose con el primero, así que era una mitad de un hombre de la mitad de la çinta para abaxo, que no cesava punto de andar de una parte a otra por la sala, molestando al cavallero, y él con su hacha desviava de sí. Y tornó la voz a deçir con más áspero y horrendo sonido: «Cayré, cayré!». Y el cavallero, cansándose de atender, respondió y dixo: «Caed quantos quisiéredes, que Dios me defenderá del diablo»; y encontinente cayeron otros dos cuartos de la çintura para arriba de un hombre, y se juntaron con los primeros, y se formó un espantable gigante con una porra o maza de hierro en la mano, y sin más detenimiento, con el mayor denuedo que pensar se puede fuese contra el cavallero, y él lo reçibió tan osadamente como si le acometiera otro hombre humano; y tales golpes se dieron, que la porra y la hacha se hicieron pedazos. Y vinieron a los brazos y un grande espacio lucharon y anduvieron tempestando asidos, sin descansar un momento. Y quiso Dios que el cavallero derrivó en tierra a aquel demonio fantasma que tal devía de ser, y desque así le tuvo habló el enemigo vencido y dixo:

«-Satis est. Yo me mido al más osado y valiente cavallero que oy vive en el mundo: mi pena es cumplida. Sávete que yo fui señor de esta tierra, y por culpas y delictos míos y de los vasallos ha mucho tiempo que estoy encantado haçiendo todo el mal que he podido y matando a muchos que aquí han entrado. Y yo salgo ya deste mal exerçiçio, y voy donde Dios tiene acordado que esté perpetuamente; y pues para ti estava guardada esta victoria, toma estas llaves y ven conmigo y entrégate de los thesoros que yo como avara guardé y no despendí, y empléalos tú mejor. Y mostróle ciertas caxas llenas de monedas antiguas de oro y plata, y desapareció aquel maldito. Y llegó el día siguiente, y salido el sol entraron algunos cavalleros del exército y también de los de la ciudad, y como le vieron vivo dieron todos muchas gracias a Dios, y la ciudad se le entregó, y el cavallero la reçibió en su obediençia, y mandó fundar en aquella casa un sumptuoso templo llamado la Victoria de Christo, porque con este nombre y con su fe havía el cavallero quedado vencedor, y llamáronle a él de ahí adelante el Osado, y de ahí vino a derivarse este nombre Osorio en sus subçesores.

Así que veis aquí cómo he oýdo esta nobela, en que yo pienso que no ay parte de verdad. Pero porque no piensen esos cavalleros Osorios que ignoramos la fábula, o que les quitamos algo que a su propósito sea (si lo es), he dicho que, bien entendido, ningun Osorio de sano juiçio açeptará ni querrá en su favor tal composición de novela, que es para espantar los niños y admirar los hombres de flaco juiçio, y para reyrse los discretos.

Fernández de Oviedo, G., Batallas y Quinquagenas, Madrid, RAH. 1983. (Ed. Amador de los Rios y Pérez de Tudela), T. I., Don Pedro Álvarez Osorio. Batalla I, Quincuagena I, Diálogo XX, págs. 197-199.

Es éste un cuento folklórico bien conocido y clasificado por Thompson, Boggs y Hansen con el Tipo 326 (The youth who wanted to learn what fear is =El joven que quiso saber lo que era el miedo); y es el motivo H. 1411,1 (Fear test: staying in haunted house where corpse drops piecemeal down chimeney $=$ Test del miedo: mientras está en una casa encantada un cadáver cae en pedazos por la chimenea). 
Al parecer es éste un cuento complejo compuesto de dos elementos: 1, un héroe, forzudo que penetra en un lugar terrorífico donde se producen ruidos y desapariciones de quienes en aquel lugar han entrado. Así nos lo cuenta Pausanias (siglo II d. de Cristo):

En esta Olimpiada y también en la que siguió a ésta, Eutymos alcanzó la corona en el pugilato. Su estatua es obra de Pitágoras y es realmente muy digna de verse. A su regreso a Italia, Eutymos luchó contra el Héroe, cuya historia es como sigue: «Ulises, dicen ellos, en sus viajes errantes después de la toma de Troya, fue arrastrado por los vientos huracanados hasta varias ciudades de Italia y Sicilia, y entre éstas llegó con sus naves a Temesa. Aquí uno de sus marineros se emborrachó y violó a una doncella, por cuya ofensa fue apedreado hasta morir por los naturales del país. Ahora bien, se dice que Ulises no se preocupó en absoluto de su pérdida y se hizo a la mar. Pero el espectro del hombre apedreado nunca cesó de dar muerte, sin distinción alguna, a las gentes de Temesa, atacando por igual a jóvenes y ancianos, hasta que, cuando los habitantes habian resuelto huir de Italia para salvarse del azote, la sacerdotisa Pytia les prohibió abandonar Temesa y les ordenó propiciarse al Héroe, erigiéndole un santuario aparte y edificándole un templo, y dándole así mismo cada año como esposa a la muchacha más bonita de Temesa. Así pues, ellos pusieron por obra las órdenes del dios y no sufrieron más horrores por parte del espectro. Pero sucedió que Eutymos llegó a Temesa precisamente en el tiempo en que el espectro estaba siendo aplacado de la forma habitual; enterado de lo que estaba ocurriendo, sintió un vivo deseo de entrar en el templo, y no solamente de entrar en él, sino también de ver a la muchacha. En cuanto la vio, primero sintió piedad y luego se enamoró de ella. La muchacha le juró casarse con él si la salvara, y Eutymos, con sus armas encima, aguardó el ataque del espectro. Ganó el combate y el Héroe fue expulsado del país y desapareció sumergiéndose en las profundidades del mar. Eutymos celebró una distinguida boda y los habitantes se vieron libres del espectro para siempre. Oí contar también otra historia acerca de Eutymos, de cómo alcanzó la más avanzada edad y, escapando una vez más a la muerte, desapareció de entre los hombres de una manera distinta. Temesa está aún habitada. Esto lo he oído, y también he visto por suerte una pintura relacionada con el asunto. Era una copia de una pintura antigua. Había en ella un joven imberbe, Sybaris, un río, el Kálabros, y una fuente, Lyka. Además de esto había el santuario de un héroe y la ciudad de Temesa, y en medio se encontraba el espectro que Eutymos echó de allí. Su color era horriblemente negro y toda su apariencia era extremadamente espantosa; llevaba en torno a su cuerpo una piel de lobo como vestidura; la inscripción que había en la pintura le daba el nombre de Lykas.

Descripción de Grecia, Libro VI, Cap. 6.

Elemento 2, el ser mágico o endemoniado que anuncia su caída por la chimenea miembro a miembro. Lo encontramos, sin aspecto truculento, en los Setenta y dos cuentos del papagayo, como episodio del cuento «El rey y su amigo». Un hombre que tiene en su cara las treinta y tres señales de la felicidad se hospeda una noche entre comerciantes:

¿Dónde le diremos que duerma? Un comerciante dijo: 
-Hermanos, yo sé un lugar apropiado; es una habitación en la que hay una hamaca.

Luego los comerciantes le dieron cien rupias de plata y le llevaron a la habitación. Después que hubo fortalecido su cuerpo con una comida, se echó a dormir. Pero por la noche resonó por dos veces en la habitación una voz que decía:

- ¿Caigo! ¡Caigo!

El comerciante dijo:

¡Cae, pues!

Y cayó un hombre de oro [estatuilla mágica cuyas partes arrancadas se reproducen solas].

El comerciante lo cogió, lo metió en su saco y, a la mañana siguiente, siguió su camino. Iba lleno de júbilo, después de haber arrojado todo lo que tenía poco valor.

Veinte cuentos de la India, Madrid, Rev. de Occidente, 1945, pág. 158.

La comparación con el primer episodio es de Erwin Rohde: «Es algo así como el joven de nuestra leyenda, que salió de su tierra para conocer el miedo». Obsérvese que es un héroe olímpico. En el segundo episodio es un hombre afortunado y piadoso - sin miedo- que permite que caiga un ser misterioso que se anuncia con voces. La caída de los miembros está aquí sustituida por su reproducción mágica al ser arrancados.

Cuándo y dónde se unieron ambos elementos es aún un misterio, pero según Thompson es un cuento «europeo: no aparece en Asia o África, y en los sitios donde aparece en el Nuevo Mundo (Chile, República Dominicana, México, Colorado, Puerto Rico), ha sido llevado obviamente por los colonos europeos... [ya que] se encuentra en todo el continente europeo, en las islas Británicas y en Islandia».

En España entra en el ciclo de Juan sin miedo n. ${ }^{\circ}$ 136-138 de los Cuentos Populares de A. M. Espinosa, y pueden verse muchas variantes en T. II, págs. 504-511; en los números 44-46 de los Cuentos populares salmantinos de Luis Cortés (cfr. las notas en el T. II, págs. 229-230), que recuerda también versiones gallegas y mallorquinas.

En relación con nuestro protagonista de apellidos Osorio quisiera hacer un par de puntualizaciones:

a) En portugués se le titula Juan Peludo, y por tanto debe de haberse asimilado a la tradición del hijo de un oso que cuenta Antonio de Torquemada en el Jardín de flores curiosas (Edición Glez. Amezúa, págs. 73-74): Habiendo huido su madre, raptada cuando joven con él y sabiendo que unos cazadores han matado al oso - su padre-, gra 
cias a sus enormes fuerzas los mata para vengarle. Lope de Vega nos presenta en Ursón y Valentín (1588-1595) al niño criado por una osa, que es posiblemente una dulcificación del tema folklórico.

La relación de una mujer con un oso aparece también en las Mil y una noches, noches 353-355 (Ed. Vernet, T. II, págs. 225-229) aunque aquí tiene como fundamental el sentido del encantamiento.

El tema ha sido clasificado por Thompson con el número B 601.1.1 (Bear steals woman and makes her his wife $=\mathrm{El}$ oso roba una mujer $\mathrm{y}$ hace de ella su esposa), aunque sólo lo localiza en la India.

b) Parece que la familia de los marqueses de Astorga, los Osorios, tuvo una amplia popularidad legendaria, ya que Antonio de Torquemada, en su Jardín de flores curiosas, recuerda otra leyenda asimilable a la de don Sancho Abarca:

Poco antes de nuestros tiempos, un caballero que se llamaba Diego Osorio, descendiente de la casa de Astorga, nació de la mesma manera [que Sancho Abarca], y cuando cortaron el vientre de la madre, fue con tan poco tiento que le dieron a él una cuchillada en una pierna, de lo cual quedó cojo y así vivió mucho tiempo. (Ed. González de Amezúa, págs. 24-25).

Lo que desde luego falta en estas versiones es cómo llegó a conocer el miedo: bien porque se le salpica con agua fría cuando duerme, bien porque un pájaro sale volando sorpresivamente cuando está descuidado, o porque ve a un fraile cuya capucha, puesto del revés, hace pensar que le han girado la cabeza, etc., etc.

\section{BIBLIOGRAFIA}

Griswold Morley, S.—«Dos notitas sobre Lope de Vega». NRFH XV, 1961, págs. 193-4. Avalle Arce, J. B. - «Un problema resuelto: Los cuartos de Osorio». NRFH XVIII, 1965-1966, págs. 166-169. 